\title{
Estudo Hidrodinâmico Quali-Quantitativo de uma unidade de flotação por ar dissolvido (FAD): O efeito do dispositivo de coleta de água flotada
}

\author{
Quali-Quantitative Hydrodynamic study of a dissolved air flotation unit \\ (DAF): The effect of the collection system
}

\author{
Rodrigo Braga Moruzzi | Marco Antonio Penalva Reali
}

Data de entrada: 22/12/2011 | Data de aprovação: 16/08/2013

DOI: http://dx.doi.org/10.4322/dae.2014.004

Resumo

O foco desse artigo foi a investigação de sistema de coleta de água de uma unidade de flotação por ar dissolvido (FAD) em escala piloto. Duas opções de coleta foram estudadas: (i) dispositivo Tipo 1, constituído de tubulação perfurada (manifold) situada próximo à superfície da região de saída da unidade FAD, após o anteparo final da mesma, e; (ii) Tipo 2, constituído de placa tipo "fundo falso", contendo orifícios e situada no fundo da zona de separação (ZS) da unidade FAD. Foram realizados ensaios qualitativos com imagens e ensaios tipo estímulo-resposta com injeção de traçador na forma de perturbação impulso. Os resultados dos ensaios parametrizados foram ajustados conforme modelos uniparamétricos de tanques em série (N-CSTR) e de dispersão de pequena (DPI) e de grande intensidade (DGI). O dispositivo Tipo 2 ("fundo falso" com orifícios) foi o mais adequado, proporcionando melhor distribuição das linhas de corrente e menor volume de zonas mortas no interior da ZS. Os resultados apontam que o modelo de tanques em série foi mais apropriado para descrever o comportamento hidrodinâmico da unidade de FAD investigada.

Palavras-chave: FAD, sistema de coleta, hidrodinâmica.

\section{Abstract}

The main article aim was to investigate the collecting system of a dissolved air flotation (DAF) unit in pilot scale. Referring to the collecting system position, two options were analyzed: (i) top manifold and (ii) bottom manifold, pipes or plates. Qualitative and quantitative essays were performed, as image and stimulusresponse tests, respectively. The results of the essays standardized were adjusted by $N$-continuous stirred tank reactors in series and theoretical models of dispersion (low and high). The bottom manifold (plates with orifices) was more appropriate. The results pointed out that the $N$-continuous stirred tank reactors in series model was more adequate to describe the hydrodynamic behavior of the DAF unit.

Key-words: DAF, collecting system, hydrodynamic.

Rodrigo Braga Moruzzi*

Possui graduação em Eng. Civil pela Universidade Federal de São Carlos (1997), mestrado em Engenharia Civil na área de Hidráulica e Saneamento pela Universidade de São Paulo (2000) e doutorado em Engenharia Civil na área de Hidráulica e Saneamento pela Universidade de São Paulo (2005), e pós-doutorado na Katholieke Universiteit Leuven (2011). Atualmente é professor assistente doutor-II da Universidade Estadual Paulista Júlio de Mesquita Filho.

\section{Marco Antonio Penalva Reali}

Possui graduação em Engenharia Civil pela Universidade de São Paulo (1981), mestrado em Engenharia Civil pela Universidade de São Paulo (1984) e doutorado em Engenharia Civil pela Universidade de São Paulo (1990). Atualmente é professor doutor da Universidade de São Paulo.

*Endereço para correspondência: Universidade Estadual Paulista Júlio de Mesquita Filho, Instituto de Geociências e Ciências Exatas de Rio Claro, Departamento de Planejamento Regional. Avenida 24 A,1515, Bela Vista, Rio Claro - SP, Brasil. CEP: $13506-900$. 


\section{Introdução}

A flotação por ar dissolvido (FAD) com recirculação pressurizada do efluente caracteriza-se por um processo trifásico de separação sólido/ líquido. Neste, microbolhas de ar são introduzidas na massa líquida, visando remoção dos flocos que são formados na etapa de pré-tratamento da água. As microbolhas são geradas a partir da dissolução do gás em parcela do efluente clarificado. Para tal, é utilizada uma unidade denominada câmara de saturação. Nesta câmara, o ar é dissolvido em valores elevados de pressão e introduzido na unidade de FAD, que opera em pressão atmosférica, precipitando assim o ar na forma de microbolhas.

Especificamente quanto à sua aplicação no tratamento de águas destinadas ao abastecimento, a FAD é reconhecida pelo seu excelente desempenho na remoção de alguns tipos de contaminantes, como as substâncias húmicas e florações algais, como afirmam Coelho, Reali e Campos (1991); Dombroski, Reali e Marchetto (1996); Edzwald e Malley (1991); Malley e Edzwald (1991); Heinanen, Jokela e Ala-peijari (1995); Marchetto e Reali (1997a); Reali e Santos (1999), entre outros. São muitos os trabalhos que demonstram as vantagens do emprego da FAD em relação aos processos de tratamento que empregam ciclo completo ou mesmo a sistemas que empregam a filtração direta. Nestes, a FAD proporciona uma maior carreira de filtração diminuindo o consumo de água para a operação de lavagem dos filtros (Schneider et al., 1991; Van Puffelen et al., 1995; Ferguson; Logsdon; Curley, 1995; Valade et al., 1996; Edzwald, 1999).

A configuração do reator de FAD deve propiciar condições para o contato e a agregação entre as partículas em suspensão no meio líquido (microbolhas de ar e flocos) assim como condições favoráveis para que os agregados sejam conduzidos até a parte superior do reator do qual podem ser removidos. Para tal, a unidade é dividida em duas regiões distintas: zona de contato (ZC) e zona de separação (ZS). A zona de contato situa-se logo após a entrada das unidades de flotação e caracteriza-se como uma região de mistura da água floculada com a água de recirculação, que é responsável pela produção de microbolhas de ar após sua despressurização em bocais difusores instalados junto à entrada da ZC. Assim, na ZC ocorre a colisão e a agregação das microbolhas de ar nos flocos. A zona de separação (ZS), por sua vez, é a região onde as condições de escoamento devem favorecer a manutenção da ligação e propiciar a ascensão do conjunto microbolhas e flocos até a superfície da ZS (Lundh; Jönsson; Dahlquist, 2002).

$\mathrm{O}$ aumento das pesquisas e da experiência adquirida com as unidades em operação proporcionou muitos avanços. Entre eles podem ser citados: mudanças nas condições de coagulação e floculação; incremento da taxa de aplicação superficial (TAS) nos tanques de FAD e alterações no sistema de fornecimento de ar (Schofield, 2000). Mais recentemente, Reali e Patrizzi (2007) demonstraram a importância da configuração da zona de contato no desempenho da FAD.

No entanto, muitas questões permanecem ainda obscuras. Entre elas, as mais contundentes referem-se às características das partículas e às condições hidrodinâmicas adequadas para o processo de FAD. Sobre os fundamentos de remoção de partículas em tanques de FAD, Edwzald e Haarhoff (2011) citam a hidrodinâmica como um dos fatores fundamentais na eficiência da interação entre bolhas e partículas. Assim, a principal motivação desse artigo foi o aprimoramento do conhecimento acerca da hidrodinâmica dos tanques de FAD e as principais questões que orientaram a consecução dos ensaios apresentados neste artigo foram: qual é o dispositivo de coleta de água flotada que propicia a distribuição de água mais uniforme no interior da zona de clarificação da unidade de FAD? Dentre três modelos teóricos uniparamétricos de escoamento, Dispersão de Grande Intensidade (DGI), Dispersão de Pequena Intensidade (DPI) e Modelo de Tanques de Mistura Completa em série (N-CSTR), qual é mais apropriado para descrever a hidrodinâmica da zona de clarificação da unidade de FAD?

$O$ projeto de unidades FAD contempla geralmente uma das seguintes opções para a coleta do efluente clarificado por flotação: i) sistema de coleta constituído por canaletas de coleta distribuídas na porção oposta à entrada da unidade; ii) sistema constituído de vários tubos paralelos contendo orifícios ao longo de sua extensão (Manifold) e distribuídos no fundo da zona de clarificação das unidades de FAD, sendo que as extremidades a montante dos tubos são fechadas e as extremidades a jusante são interligadas ao canal de saída do flotador, ou, iii) uma variação dessa última opção,em que os tubos paralelos com orifícios são substituídos por fundo falso 
contendo orifícios situados também na parte inferior da zona de separação e interligado ao canal de saída da unidade.

Amato e Wicks (2009) realizaram simulações, empregando modelos computacionais fluido-dinâmicos, visando diagnosticar o efeito do incremento da taxa de aplicação superficial de uma unidade plena de FAD com saída superior na porção oposta da unidade. Os padrões de escoamento nas zonas de contato (ZC) e de separação (ZS) da unidade foram avaliados preferencialmente em vetores bidimensionais (2D), dada a complexidade computacional requerida para a análise tridimensional, como discutido em Bondelind et al. (2010), investigando o sistema trifásico (água, ar e sólidos). Os autores verificaram que as simulações computacionais, embora complexas, nem sempre refletiam os resultados medidos nas unidades de FAD, todavia, pequenas alterações hidrodinâmicas repercutiram em maior intensidade na qualidade da água produzida pelo sistema.

Lundh, Jönsson e Dahlquist (2002) apresentaram resultados de um estudo de mapeamento da zona de contato de uma unidade piloto de FAD com geometria retangular, utilizando sonda ultrassônica. Os autores investigaram uma zona de contato com placa defletora a $90^{\circ}$ (altura de 60 a $110 \mathrm{~cm}$ ) e seção transversal constante (largura fixa de 16, 24 ou $36 \mathrm{~cm}$ ). Shawwa e Smith (1998), por sua vez, estudaram uma coluna de flotação de $10 \mathrm{~cm}$ de diâmetro e $100 \mathrm{~cm}$ de altura, por meio de ensaios estímulo-resposta. As conclusões apresentadas por Lundh, Jönsson e Dahlquist (2002) convergiram para as mesmas extraídas por Shawwa e Smith (1998), utilizando ensaios do tipo estímulo e resposta, apontando ambos os autores que a zona de contato possui regiões com escoamentos distintos: a parte inferior caracterizada por intensa mistura e a parte superior com escoamento tendendo ao pistonado. Todavia, Moruzzi (2005), que utilizou o mesmo equipamento de Lundh, Jönsson e Dahlquist (2002), encontrou um diferente padrão de escoamento no interior da unidade. A configuração diferenciada dos defletores (com seção transversal variada) foi atribuída como causa do comportamento diferenciado, resultando em um padrão de recirculação interna do escoamento bastante definido, ao longo da altura e da largura. Verificou-se também em Moruzzi (2005) e Moruzzi e Reali (2011) que existe evidente relação entre o tempo de detenção na zona de contato $\left(\mathrm{Td}_{z c}\right)$, seu consequente valor de taxa de aplicação superficial $\left(\mathrm{TAS}_{\mathrm{zc}}\right.$ ), e a taxa de recirculação de água saturada (p) com a eficiência do processo de $\mathrm{FAD}$ na remoção de cor aparente e turbidez. Resultados da ordem de 90\% para cor aparente e turbidez foram obtidos para $\mathrm{Td}_{\mathrm{zc}} \mathrm{de}$ 40s $\left(\mathrm{TAS}_{\mathrm{zc}}\right.$ de $\left.60 \mathrm{~m} \cdot \mathrm{h}^{-1}\right)$ e p de $0,1(\mathrm{v} / \mathrm{v})$.

Reali e Patrizzi (2007) realizaram um estudo mais completo acerca do padrão de escoamento na zona de contato e sua consequência na eficiência de remoção de cor aparente e turbidez, sobre diversas configurações da zona de contato. Os referidos autores utilizaram o mesmo equipamento usado por Lundh, Jönsson e Dahlquist (2002) e concluíram que, em geral, o padrão de escoamento foi similar ao observado por aqueles autores. Todavia, contrariamente a Lundh, Jönsson e Dahlquist (2002), o melhor desempenho da unidade piloto de FAD foi obtido quando se empregou a Taxa de aplicação superficial na zona de contato $\left(\right.$ TAS $_{z c}$ ) de $180 \mathrm{~m} \cdot \mathrm{h}^{-1}$ associado com 34 segundos de tempo de detenção na zona de contato, resultando em 98,3\% de remoção de turbidez e 96,4\% de remoção de cor aparente.

Outro estudo, apresentado por Lakghomi, Lawryshyn e Hofmann (2012) investigaram o padrão de escoamento no sistema trifásico de uma unidade de FAD por meio da aplicação de modelagem fluido-dinâmica computacional. Mantendo fixas as dimensões da unidade de FAD, os autores concluíram que a estratificação causada pela presença de microbolhas induz ao escoamento horizontal na zona de clarificação da unidade, incorrendo em benefícios ao processo.

Embora de suma importância para o desempenho de unidades de FAD, há ainda poucos trabalhos na literatura acerca do tema, centrando-se a maioria dos casos em estudos experimentais em unidades tubulares ou em estudos de simulação fluidodinâmica.

Neste artigo, alguns aspectos hidrodinâmicos de uma unidade piloto FAD de alta taxa, que foi proposta e descrita por Reali e Santos (1999), foi avaliada quali-quantitativamente para duas diferentes configurações de sistemas de coleta de água flotada em dois diferentes modos de operação do piloto: em modo convencional ou em modo com alta taxa (com inserção de módulo com lamelas na ZS) . Adicionalmente, para a melhor situação foi verificado o modelo matemático de escoamento mais adequado para descrever o 
comportamento hidrodinâmico na zona de separação da unidade objeto de estudo.

Objetivo: Determinar a condição de coleta de água flotada da unidade piloto e verificar o modelo mais adequado para descrever o comportamento do escoamento no interior da unidade FAD.

\section{Material e métodos \\ Descrição da unidade piloto de FAD utilizada no estudo}

A instalação piloto de flotação por ar dissolvido (FAD) utilizada nesta pesquisa (capacidade de 1500 L.h ${ }^{-1}$ ) foi proposta e descrita por Reali e Santos (1999). Ela foi construída em acrílico e constituída de uma unidade de mistura rápida tipo tubular, uma unidade de floculação mecanizada com três compartimentos em série, associada a uma unidade de flotação que pode operar tanto do modo convencional quanto do modo de alta taxa. Para operação com alta taxa, é introduzido em seu interior um módulo composto por placas planas paralelas, devidamente dispostas de modo a promover escoamento vertical com baixos números de Reynolds (Reali e Santos, 1999). Na Figura 1 é mostrada uma fotografia da instalação piloto de flotação por ar dissolvido utilizada no presente estudo. Na referida fotografia a instalação piloto encontra-se montada para a operação com alta taxa, ou seja, com o módulo lamelar instalado no interior da zona de separação.

A unidade de floculação pode ser operada com uma, duas ou três câmaras em série e os agitadores do sistema de floculação possuem controles

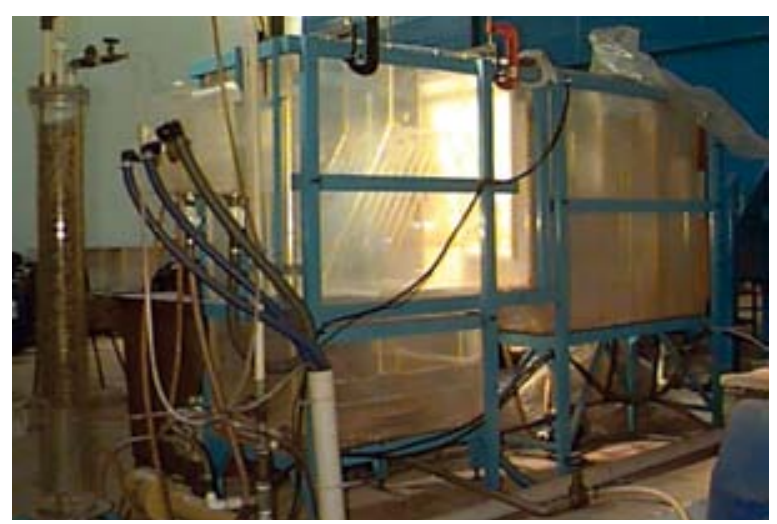

Figura 1 - Fotografia da instalação piloto de flotação por ar dissolvido com módulo de alta taxa instalado em seu interior. de rotação independentes e são do tipo de eixo vertical com paletas paralelas ao eixo. Cada agitador tem quatro braços e duas paletas por braço.

Esta unidade de flotação possui, instalado junto à sua entrada, um dispositivo de despressurização da vazão de recirculação proveniente da câmara de saturação (registro de agulha). A região situada logo a jusante deste ponto é chamada zona de contato. Esta é a região onde ocorre o encontro entre os flocos e as microbolhas de ar geradas após a despressurização da vazão de recirculação. Após a zona de contato, encontra-se a zona de separação ou clarificação, onde ocorre a flotação propriamente dita. No interior da zona de separação dessa unidade piloto é possível a instalação de um módulo especial, contendo placas planas paralelas inclinadas. A inserção de tal módulo proporciona escoamento vertical associado a baixos números de Reynolds, o que permite a operação a altas taxas. Acima da zona de separação, situa-se a região de acumulação de lodo. Os flocos removidos permanecem na superfície da zona de acumulação, formando uma camada de lodo.

Parte da água clarificada na unidade de flotação foi recalcada para a câmara de saturação por uma bomba centrífuga multiestágio de alta pressão (Bomba Jacuzzi $60 \mathrm{~Hz}$ ) e monitorada através de medidor de vazão Enginstrel/ Engematic. A câmara de saturação adotada é do tipo com recheio, sendo este constituído de anéis de PVC com diâmetro de $30 \mathrm{~mm}$ e comprimento de $20 \mathrm{~mm}$, conforme proposto por Reali e Campos (1992). Na parte superior da câmara é injetado ar comprimido de tal maneira que o recheio fique envolto por ar. Assim, ao passar pelo recheio, a água submetida à alta pressão é saturada com ar.

\section{Condições dos ensaios e dispositivos investigados}

Foram realizados ensaios alterando-se a taxa de aplicação superficial para cada sistema de coleta de água flotada. Após a definição da melhor alternativa foi variada a recirculação de água pressurizada (p) que fornece microbolhas ao sistema de FAD para cada condição operacional (convencional e alta taxa).

Foram investigados dois pontos para instalação dos dispositivos de coleta de água flotada: manifold perfurado superior, funcionando como vertedor livre (dispositivo Tipo 1) e "fundo falso" inferior, operando como vertedor afogado (dis- 

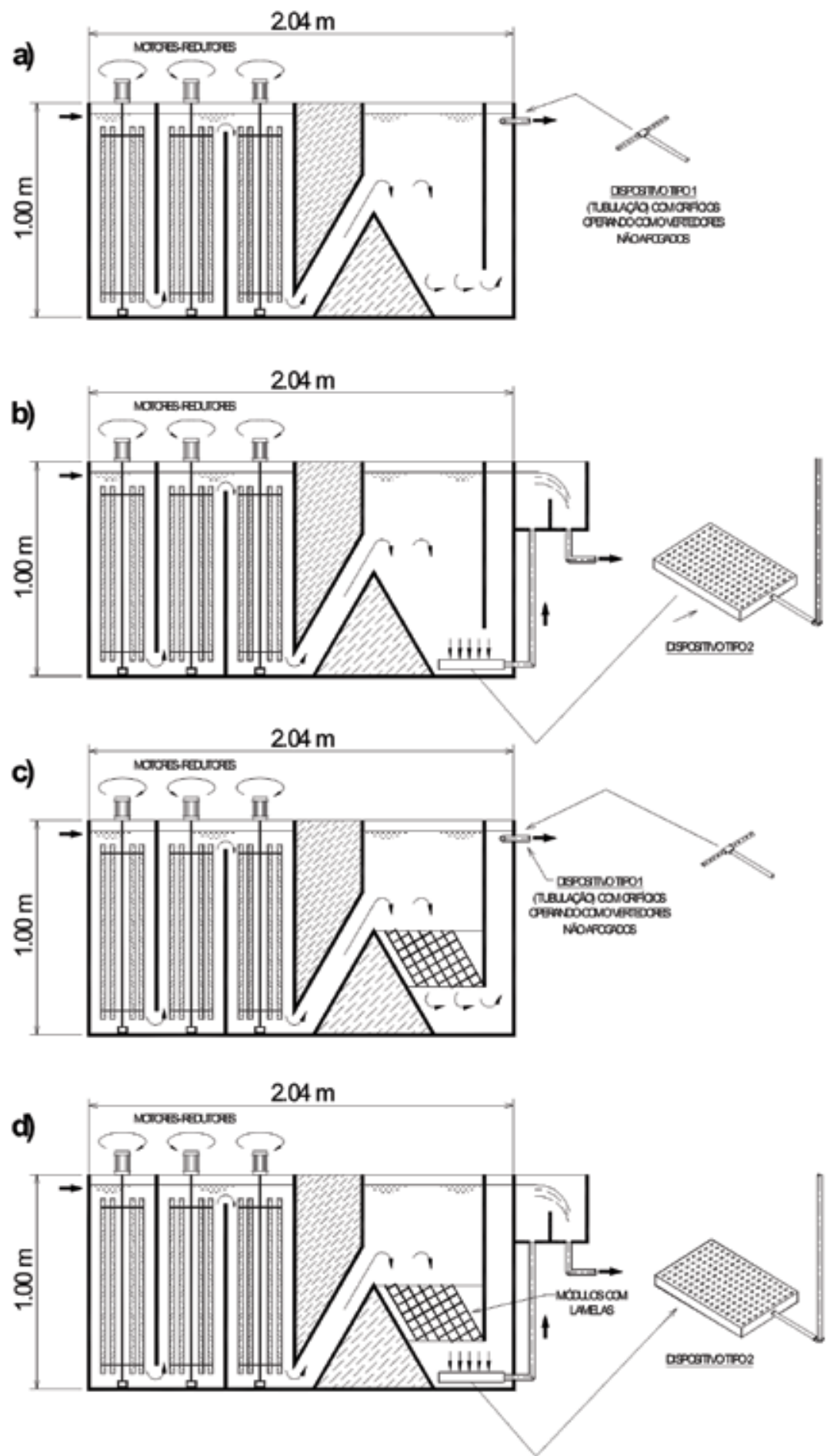

Figura 2 - Esquemas mostrando os modos de operação da instalação piloto de flotação por ar dissolvido de alta taxa com módulo contendo placas planas paralelas e escoamento vertical proposta por Reali e Santos (1999): a) operação convencional com dispositivo de coleta de água flotada Tipo 1; b) operação convencional com dispositivo de coleta de água flotada Tipo 2; c) operação com módulo lamelar de alta taxa com dispositivo de coleta de água flotada Tipo 1, e, d) operação com módulo lamelar de alta taxa com dispositivo de coleta de água flotada Tipo 2. 
positivo Tipo 2). O manifold superior constituiu-se de um tubo perfurado de comprimento igual à largura da unidade no qual a água flotada vertia livremente para seu interior. O "fundo falso" afogado (dispositivo Tipo 2) ocupava toda a área do fundo da zona de separação da piloto.

A Figura 2 apresenta esquemas ilustrativos da referida instalação piloto em suas diferentes configurações. Nessa figura são apresentadas as duas opções de configurações para operação convencional ou com alta taxa, assim como os dois dispositivos de coleta de água flotada investigados: i) Tipo1, constituído de tubulação perfurada (manifold com orifícios operando como vertedores livres) instalada junto à superfície da zona de saída do flotador, na região situada entre o anteparo de saída e a parede final do flotador; e, ii) Tipo 2, "fundo falso" constituído de placa dupla de acrílico (com orifícios na placa superior) instalado na parte inferior (no fundo) da zona de separação da piloto.

Na Figura 3 é mostrada uma fotografia do dispositivo Tipo 2. Preliminarmente, os resultados foram analisados qualitativamente por meio de ensaios fotográficos.

A Tabela 1 apresenta os principais dados do projeto (diâmetros, espaçamentos e números de orifícios por unidade de área) dos dois dispositivos de coleta de água flotada, objetos do presente estudo, ou seja, dos dispositivos designados por Tipo 1 e Tipo 2, cujos desenhos esquemáticos encontram-se mostrados na Figura 1.

Foram realizados ensaios com aplicação de traçadores e subsequente aquisição de imagens do interior das zonas de contato e de separação. O azul de metileno e a rodamina foram utilizados como traçadores para obtenção de contraste e acrescidos um após a saída do outro para evidenciar a presença de regiões estagnadas no interior do reator. Esses ensaios balizaram as decisões posteriores no que concerne aos ensaios de estímulo e resposta, auxiliando a definir as condições de estudo subsequentes a serem investigadas. Para esses ensaios de imagens, as seguintes condições de configuração da instalação piloto de flotação foram avaliadas:

i) Piloto com módulo lamelar de alta taxa e com dispositivo de coleta Tipo 1. Nessa configuração foram variadas: os valores da taxa de aplicação superficial na zona de separação $\left(\mathrm{TAS}_{z s}\right)$ de 200 , 300 e de $500 \mathrm{~m}^{3} \cdot \mathrm{m}^{-2} \cdot \mathrm{d}^{-1}$; o valor da taxa de aplicação superficial na zona de contato $\left(\mathrm{TAS}_{z \mathrm{zc}}\right)$ e o valor de tempo de detenção hidráulico na zona

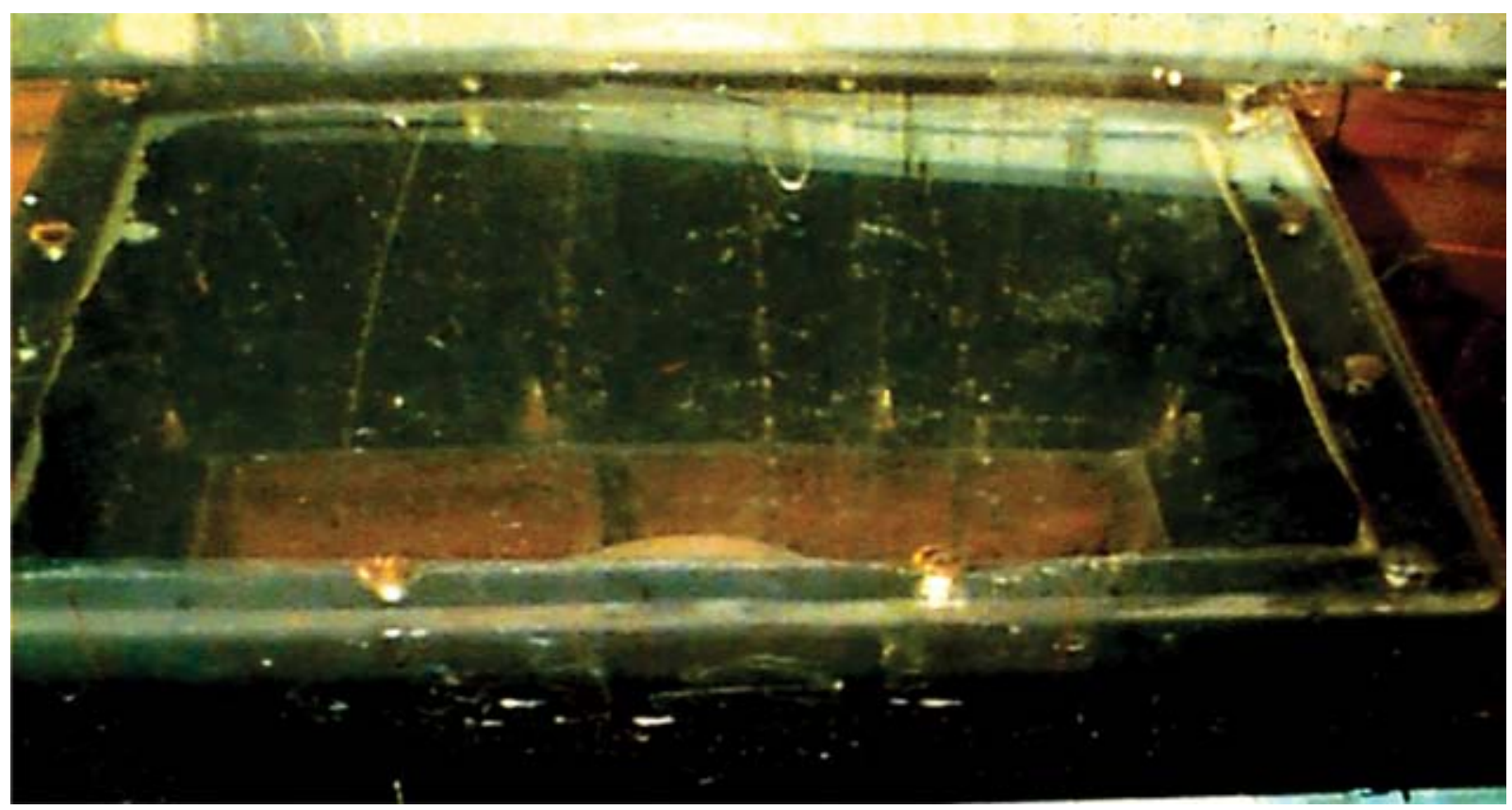

Figura 3 - Fotografia da placa com orifícios "(fundo falso)" utilizado para coleta de água na porção inferior da zona de clarificação (dispositivo Tipo 2). 


\begin{tabular}{c|c|c|c|c} 
Tipo de dispositivo & $\begin{array}{c}\text { Diâmetro dos } \\
\text { orifícios }(\mathrm{mm})\end{array}$ & $\begin{array}{c}\text { Número de } \\
\text { orifícios }(\mathrm{N})\end{array}$ & $\begin{array}{c}\text { Concentração de } \\
\text { orifícios }\left(\mathrm{N} / \mathrm{m}^{2}\right)^{\mathrm{a}}\end{array}$ & $\begin{array}{c}\text { Conc. linear de } \\
\text { orifícios }(\mathrm{N} / \mathrm{m})^{\mathrm{b}}\end{array}$ \\
\hline Tipo 1 & 5 & 9 & N.A & 18 \\
\hline Tipo 2 & 2 & 66 & 1200 & N.A \\
\hline
\end{tabular}

a Número de orifícios por unidade de área do "fundo falso" que constitui o dispositivo Tipo 2 instalado no fundo da zona de separação do flotador.

${ }^{b}$ Número de orifícios por metro linear de tubulação de coleta de água instalada ao longo da largura do flotador, próximo à superfície de sua região de saída (dispositivo Tipo 2)

${ }^{c}$ Não se aplica

Tabela 1: Características principais dos orifícios dos dispositivos de coleta de água flotada investigados.

de contato $\left(\mathrm{Td}_{\mathrm{zc}}\right)$ de $25 \mathrm{~m} \cdot \mathrm{h}^{-1}$ e $90 \mathrm{~s}$, respectivamente; o valor de fração de recirculação pressurizada a $450 \mathrm{kPa}(\mathrm{p})$ foi mantido fixo em 0,10 .

ii) Piloto com módulo lamelar de alta taxa e com dispositivo de coleta Tipo 2. Nessa configuração foram variadas: o valor da taxa de aplicação superficial na zona de contato $\left(\mathrm{TAS}_{z c}\right)$ e o valor de tempo de detenção hidráulico na zona de contato $\left(\mathrm{Td}_{z c}\right)$ de 25 ou $60 \mathrm{~m} \cdot \mathrm{h}^{-1}$ e 90 ou $40 \mathrm{~s}$, respectivamente; os valores de fração de recirculação pressurizada a $450 \mathrm{kPa}(\mathrm{p})$ de 0,10 ou 0,05. Para essas condições, o valor da taxa de aplicação superficial na zona de separação $\left(\right.$ TAS $_{z S}$ ) foi mantido fixo em $460 \mathrm{~m}^{3} \cdot \mathrm{m}^{-2} \cdot \mathrm{d}^{-1}$

iii) Piloto com operação no modo convencional (sem módulo lamelar) e com dispositivo de coleta Tipo 2. Nessa configuração foram testados os valores da taxa de aplicação superficial na zona de contato $\left(\right.$ TAS $_{z c}$ ) e o valor de tempo de detenção hidráulico na zona de contato $\left(\mathrm{Td}_{\mathrm{zc}}\right)$ de 25 ou 60 m.h. ${ }^{-1}$ e 90 ou 40 s, respectivamente. 0 valor da taxa de aplicação superficial na zona de separação $\left(\right.$ TAS $_{z s}$ ) foi fixado em $200 \mathrm{~m}^{3} / \mathrm{m}^{2}$.dia e $\mathrm{o}$ valor de fração de recirculação pressurizada a $450 \mathrm{kPa}(\mathrm{p})$ foi fixado em 0,10 .

\section{Ensaios de estimulo e resposta}

Utilizou-se um volume definido (20ml) de solução concentrada com $\mathrm{NaCl}$, na forma de injeção tipo pulso, para a realização dos ensaios de estímulo e resposta. Um eletrodo submerso foi utilizado para a coleta de amostras em intervalo de registro de 30 segundos para que o número de pontos não excedesse a capacidade máxima de armazenamento de dados do equipamento utilizado (TI-89 Texas Instruments conjugado a CBL2 e software TI-Graph Link 89).

Os dados foram tratados, seguindo os procedimentos apresentados em Levenspiel (1999).
Foram construídas as curvas normalizadas do traçador (E $\theta)$ e o tempo adimensional $(\theta)$. Os dados experimentais foram ajustados utilizando-se os modelos de dispersão de grande intensidade (DGI) para $1 / \mathrm{Pe}>0,01$, e reator aberto $(D \neq 0)$, de pequena intensidade (DPI) para $1 / \mathrm{Pe}<0,01$, e tanques em série (N-CSTR), correspondentes às Equações 1, 2 e 3, respectivamente.

$$
E_{\theta}=\frac{1}{2 \sqrt{\pi \theta(D / u . L)}} e^{\left[-\frac{(1-\theta)^{2}}{4 \theta(D / H . L)}\right]}
$$

$$
E_{\theta}=\frac{1}{2 \sqrt{\pi(D / u . L)}} e^{\left[-\frac{(1-\theta)^{2}}{4(D / u \cdot L)}\right]}
$$

$$
\mathrm{E}_{\theta}=\frac{\mathrm{N}(\mathrm{N} \theta)^{\mathrm{N}-1}}{(\mathrm{~N}-1) ! \cdot \mathrm{e}^{\mathrm{N} \theta}}
$$


As variáveis empregadas nos modelos são apresentadas nas Equações 4 e 5.

$$
\sigma^{2}=\frac{\int_{0}^{\infty}(t-t)^{2} \cdot E(t) \cdot d t}{\int_{0}^{\infty} E(t) \cdot d t}
$$

$$
\sigma_{0}^{2}=\frac{\sigma^{2}}{(t)^{2}}=\frac{\int_{0}^{\infty}(\theta-\theta)^{2} \cdot E(\theta) \cdot d \theta}{\int_{0}^{\infty} E(\theta) \cdot d \theta} ; \bar{\theta}=1
$$

Em que:

$\theta=$ tempo adimensional dado por $_{\vec{t}}^{t}$;

$\overline{\boldsymbol{t}}=$ tempo de detenção hidráulica (T);

$D=$ coeficiente de dispersão longitudinal $\left(L^{2} \cdot T^{1}\right)$;

$u=$ velocidade média de percurso longitudinal $\left(L . T^{1}\right)$;

$L=$ comprimento $(L)$;

$P e=\frac{l . v}{D}$ (Número de Peclet)(-);

$N=$ número de reatores em série (-);

As condições investigadas estão apresentadas na Tabela 2.

\section{Resultados e Discussão}

Os resultados de cada conjunto de ensaios são apresentados em figuras dispostas sequencialmente tendo como início o momento de injeção de traçador. Cada figura refere-se a uma das quatro configurações da unidade piloto investigadas, que foram descritas anteriormente no item Material e Métodos. Para cada configuração foram variados os valores de Taxa de Aplicação Superficial na zona de separação (TAS) e de porcentagem de recirculação de água saturada (p).

Ensaios efetuados na piloto com módulo lamelar e dispositivo de coleta de água flotada Tipo 1 (Manifold superior)

Os resultados preliminares confirmaram a existência de desequilíbrio do escoamento na zona de clarificação da unidade quando operando no modo de alta taxa (com módulo lamelar) e dispositivo de coleta de água flotada Tipo 1 . As Figuras 4,5 e 6 mostram claramente a presença de curtos-circuitos que foram acentuados com o incremento da taxa de aplicação superficial, quando o sistema de coleta de água flotada foi constituído de manifold livre, localizado no extremo superior da unidade piloto. Esta informação é relevante, pois trata-se de dispositivo de coleta de água flotada utilizada com frequência em unidades FAD convencionais. Ou seja, os resultados mostram que para unidades com módulo lamelar, o dispositivo Tipo 1 mostrou-se inadequado.

Na Figura 4, a imagem à esquerda apresenta o momento da entrada do contraste (azul de metileno) na zona de separação da unidade de FAD. Verifica-se claramente a existência de caminhos

\begin{tabular}{c|c|c|c}
$\begin{array}{c}\text { Modo de operação } \\
\text { da piloto }\end{array}$ & TASz.s $\left(\mathrm{m}^{3} \mathrm{~m}^{-2} \mathrm{dia}-1\right)\left[\mathrm{m} \cdot \mathrm{h}^{-1}\right]^{\mathrm{a}}$ & $\operatorname{TAS}_{\mathrm{z.c}}\left(\mathrm{m} \cdot \mathrm{h}^{-1}\right) ; \mathrm{td}_{\mathrm{z.c}}(\mathrm{s})^{\mathrm{b}}$ & $\mathrm{p}(-)^{\mathrm{c}}$ \\
\hline \multirow{2}{*}{$\begin{array}{c}\text { FAD Convencional } \\
\text { (sem lamelas) }\end{array}$} & $200[8,33]$ & $25 ; 90$ & 0,10 \\
\cline { 2 - 4 } & & $60 ; 40$ & 0,05 \\
\cline { 2 - 3 } & $125[5,21]$ & $60 ; 40$ & 0,10 \\
\hline
\end{tabular}

a Taxa de Aplicação Superficial na zona de clarificação.

${ }^{b}$ Taxa de Aplicação Superficial na zona de contato; Tempo de detenção na zona de contato (cálculos com base na seção média e no volume útil da zona de contato).

c razão de recirculação (volume/volume).

Tabela 2: Condições investigadas para os ensaios estímulo-resposta na unidade piloto de FAD com operação no modo convencional e taxa de aplicação superficial na zona de separação $\left(T A S_{z S}\right)$, tempo de detenção na zona de contato $\left(\right.$ td $\left._{z c}\right)$ e fração de recirculação pressurizada (p) à pressão de $450 \mathrm{kPa}$ 

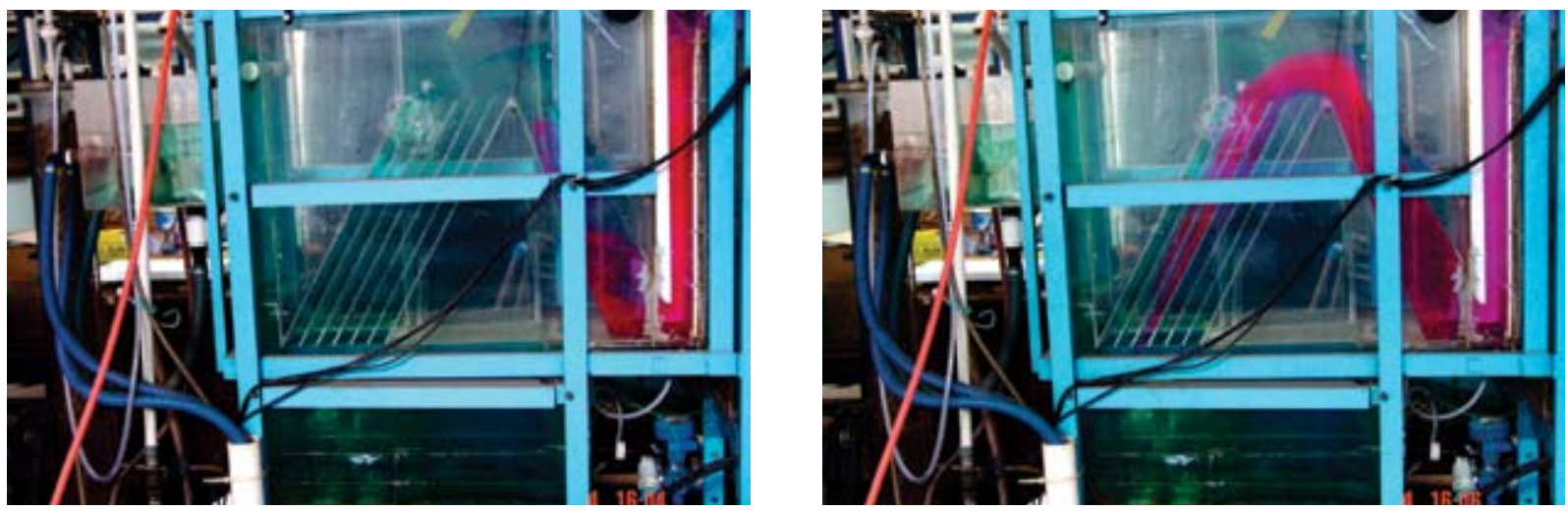

Figura 4- Algumas das imagens dos ensaios com uso de traçador que envolveram a definição das condições de coleta da água flotada na unidade, operando com modo de alta taxa. Ensaios realizados com a taxa de $200 \mathrm{~m}^{3} \cdot \mathrm{m}^{-2} \cdot \mathrm{d}^{-1}, p=0,1$ e $T d_{z c}=90 \mathrm{~s}$ e a saída feita através de tubulação perfurada localizada na parte superior da zona de saída da piloto (dispositivo Tipo 1).

preferenciais. A imagem subsequente da mesma figura mostra a entrada da rodamina no sistema e a permanência do azul de metileno em algumas das lamelas, caracterizando a presença de zonas mortas.

A Figura 5 mostra que incremento da TAS de 200 para $300 \mathrm{~m}^{3} / \mathrm{m}^{2}$.dia ${ }^{-1}$ acentuou o aparecimento de regiões com curto-circuito, deslocando o fluido para as placas localizadas nas porções posteriores.

A Figura 6 evidencia o aumento da distribuição irregular do escoamento, a medida que a placa mais distante da entrada tem escoamento com vazão visivelmente maior que as demais, fato facilmente visualizado por meio de seu preenchimento com traçador, antes que o mesmo completasse os espaços entre as demais lamelas do módulo.

Ao contrário, observa-se que as placas próximas à entrada são lentamente preenchidas com os traçadores.

Em todas as condições investigadas verificou-se a presença de zonas mortas e curto-circuitos na zona de separação. Estes padrões irregulares de escoamento podem prejudicar a eficiência de separação de partículas pelo flotador lamelar, uma vez que algumas regiões interlamelares são sobrecarregadas, enquanto outras operam submetidas a taxas aquém da sua capacidade.

Os ensaios subsequentes visaram corrigir o problema através da mudança da configuração e do posicionamento do dispositivo de coleta de água flotada, passando da região superfícial da zona de saída para o fundo da zona de separação,
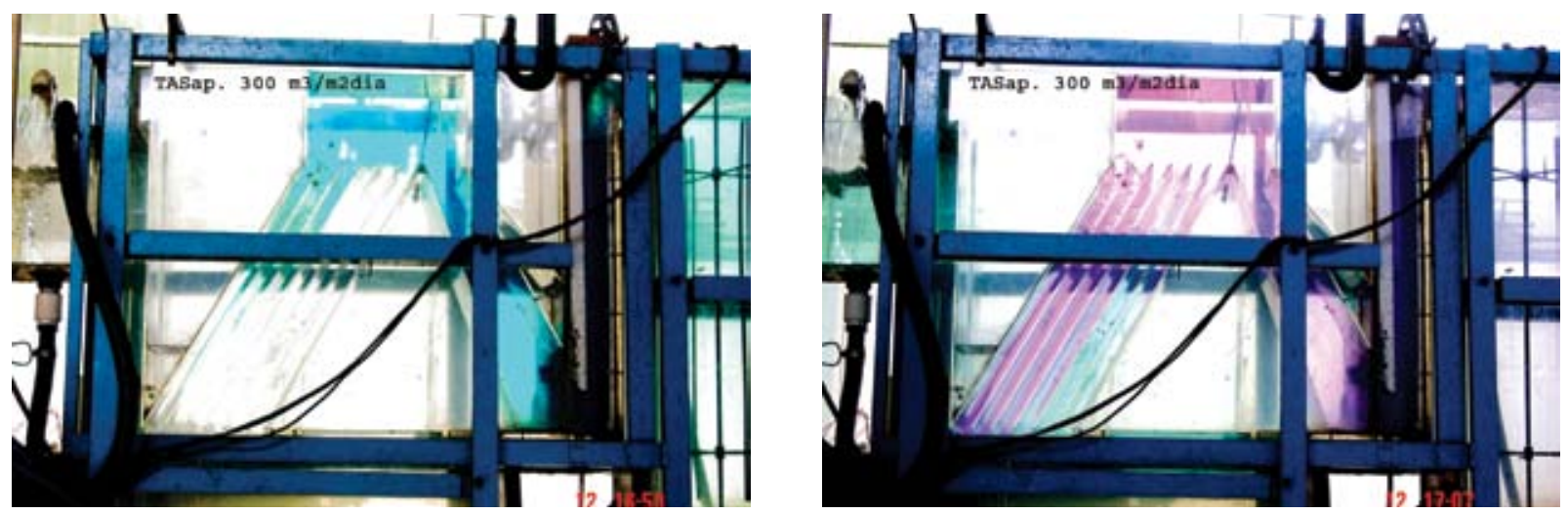

Figura 5 - Algumas das imagens dos ensaios com uso de traçadores mostrando a distribuição do escoamento de líquido entre as lamelas em dois momentos subsequentes da unidade operando no modo de alta taxa. Taxa de $300 \mathrm{~m}^{3} \cdot \mathrm{m}^{-2} \cdot \mathrm{d}^{-1}, p=0,1$ e $t d_{z c}=90$ e a saída feita através de tubulação perfurada localizada na parte superior da zona de saída da piloto (dispositivo Tipo 1). 

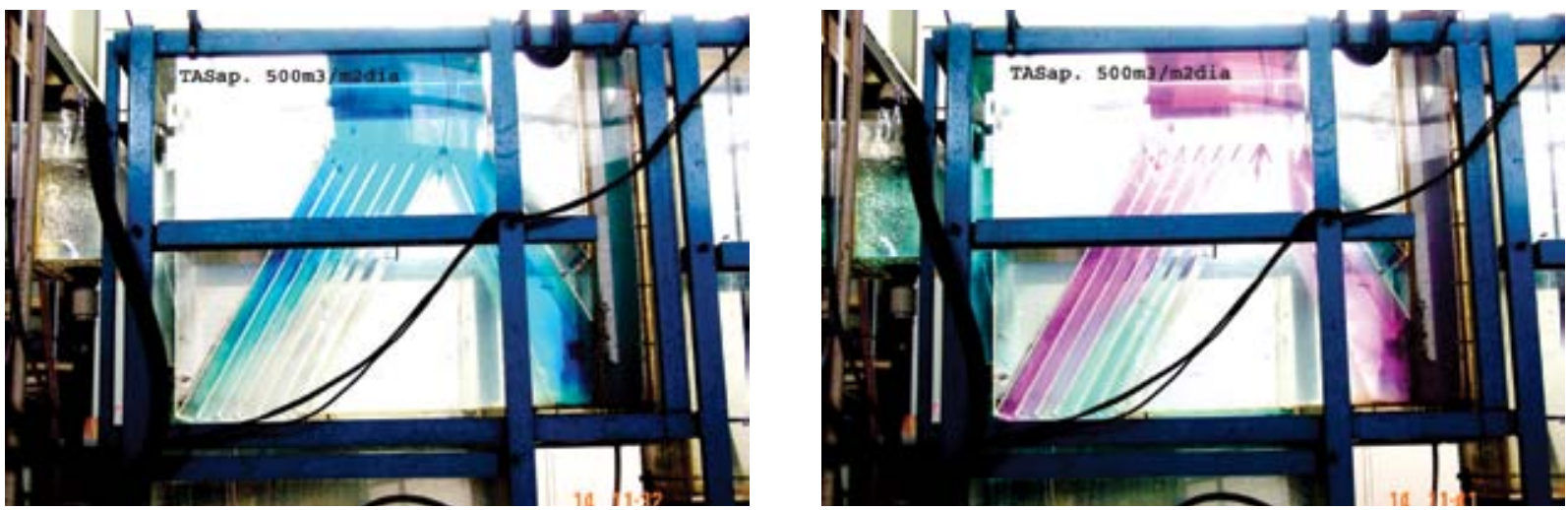

Figura 6 - Algumas das imagens dos ensaios com uso de traçadores mostrando a distribuição do escoamento de líquido entre as lamelas em dois momentos subsequentes da unidade operando no modo de alta taxa. Taxa de aplicação superficial no flotador de $500 \mathrm{~m}^{3} \cdot \mathrm{m}^{-2} \cdot \mathrm{d}^{1}, p=0,1$ e $T d_{z c}=90$ e a saída da água flotada feita através de tubulação perfurada localizada na parte superior da zona de saída da piloto (dispositivo Tipo 1).

bem como, alterando-se as dimensões, número e a disposição dos furos que compuseram a área de coleta de água, ou seja, trocando-se o dispositivo Tipo 1 pelo dispositivo Tipo 2, descritos anteriormente.

Ensaios efetuados na piloto com módulo lamelar e dispositivo de coleta de água flotada Tipo 2 ("fundo falso" inferior)

Parte dos resultados desses ensaios é apresentada na Figura 7 e foi realizada variando-se também a razão de recirculação $(\mathrm{p})$ de 0,05 a 0,10 , com tempo de detenção na zona de contato da unidade piloto $\left(\mathrm{Td}_{z c}\right)$ de $40 \mathrm{~s}$.

Observa-se uma melhor distribuição do líquido em escoamento através das placas. No entanto, as linhas de corrente não obedecem a uma distribuição equânime, dando preferência às primeiras placas a partir da saída da zona de contato.
Deve-se considerar, porém, o fator de redução de escala como interferente na distribuição do escoamento. A Figura 8 mostra os resultados referentes a TAS de $460 \mathrm{~m}^{3} \cdot \mathrm{m}^{-2} \cdot \mathrm{d}^{-1}$, para recirculação de $10 \%$ (p igual a 0,10 ) e tempo de detenção na zona de contato $\left(\mathrm{Td}_{\mathrm{zc}}\right)$ de $40 \mathrm{~s}$.

Ensaios efetuados na piloto, operando no modo convencional e dispositivo de coleta de água flotada Tipo 2 ("fundo falso" inferior)

As figuras 10 e 11 mostram algumas das imagens obtidas durante a consecução destes ensaios. Nas referidas fotografias se observa que parcela da zona de separação foi diminuída com inserção de placas de isopor no interior da unidade piloto. Dessa forma, a área foi reduzida para alcançar os valores de $\mathrm{TAS}_{7 \mathrm{~s}}$ desejados.

Os resultados permitiram verificar que o modo de operação convencional obteve distribuição
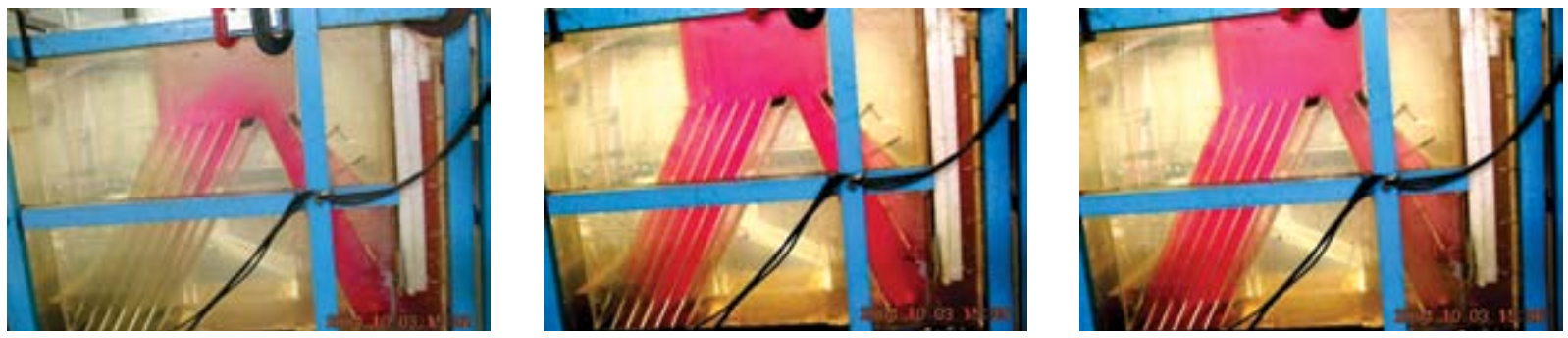

Figura 7 - Algumas das imagens dos ensaios com uso de traçadores, mostrando a distribuição do escoamento de líquido entre as lamelas em três momentos subsequentes da unidade, operando no modo de alta taxa. Taxa de aplicação superficial no flotador de $460 \mathrm{~m}^{3} \cdot \mathrm{m}^{-2} \cdot \mathrm{d}^{-1}$ e a saída da água flotada $p=0,05, T d_{z c}=40$ s e a saída de água flotada feita através de placa com orifícios localizada logo abaixo do conjunto de lamelas (dispositivo Tipo 2). 

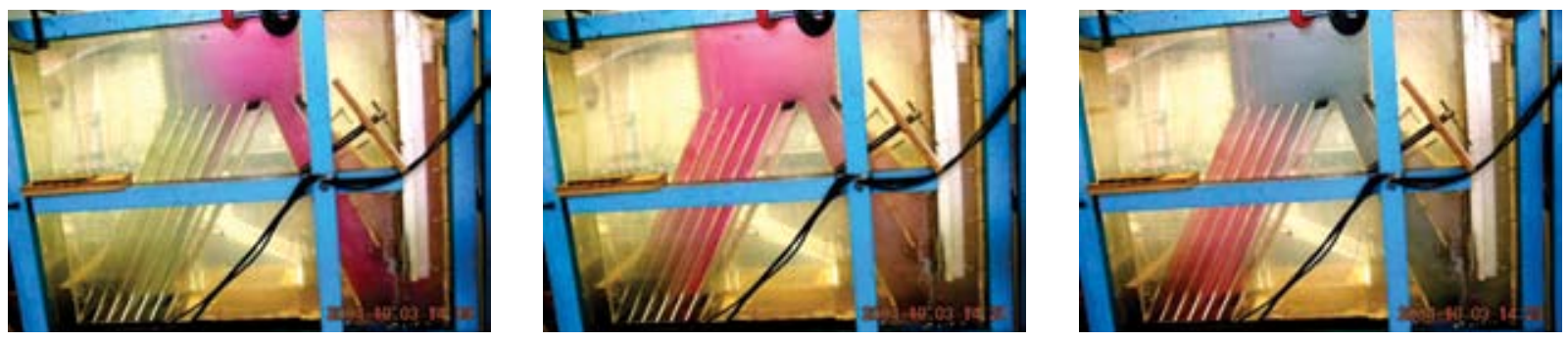

Figura 8 - Algumas das imagens dos ensaios com uso de traçadores, mostrando a distribuição do escoamento de líquido entre as lamelas em três momentos subsequentes da unidade, operando no modo de alta taxa. Taxa de $460 \mathrm{~m}^{3} \cdot \mathrm{m}^{-2} \cdot \mathrm{d}^{-1}, p=0,10, T d_{z c}=40 \mathrm{~s}$ e a saída de água flotada feita através de placa com orifícios localizada logo abaixo do conjunto de lamelas (dispositivo Tipo 2).

mais equânime de água no interior da zona de clarificação quando comparada aos ensaios com módulos de placas. Destaca-se que foi utilizado o mesmo sistema de coleta empregado nos ensaios efetuados no modo de alta taxa. Tal fato deve-se, principalmente, ao menor valor de $\mathrm{TAS}_{z c}$ empregada para o sistema de coleta de água flotada constituído por placas por orifícios (dispositivo Tipo 2).

Ensaios de estímulo e resposta efetuados com piloto, operando no modo convencional e dispositivo de coleta de água flotada Tipo 2

A Figura 12 apresenta os resultados dos ensaios de estímulo e resposta para a unidade piloto de FAD, contemplando a zona de contato e a zona de separação, e operando no modo convencional com dispositivo de coleta de água flotada constituído de fundo falso (placa) com orifícios (dispositivo Tipo 2). Nesses ensaios a unidade foi operada com TAS $_{z S}$ de $125 \mathrm{~m}^{3}$. $\mathrm{m}^{2}$. dia- ${ }^{-1}, \mathrm{Td}_{\mathrm{zc}}$ teórico de 40 s e razão de recirculação (p) de 0,10 . Os resultados não indicaram a presença de zona morta, pois o valor de $\Theta$ foi sempre $<1$ (Figura 12-a). A Tabela contida na Figura 12-b mostra que o conjunto possuiu uma dispersão moderada tendendo a baixa dispersão, pois o número de dispersão foi de 0,10 com grande extensão do escoamento tendendo ao pistonado, pois o tempo de residência modal foi de 0,75 e o valor de $\sigma^{2}$ foi de 0,21 . A Figura 12-b, referente ao modelo de tanques em série, mostra um bom ajuste da reta de regressão aos pontos experimentais. No entanto, o modelo de pequena dispersão (Figura 12-c) mostrou-se mais adequado para descrever o comportamento do fluxo da unidade de flotação como um todo (zona de contato + zona de separação).

A Figura 13 apresenta os resultados dos ensaios de estímulo e resposta para o tanque de flotação da unidade piloto de FAD investigada, operando com $\mathrm{TAS}_{z . \mathrm{S}}$ de $200 \mathrm{~m}^{3} \cdot \mathrm{m}^{2} \cdot \mathrm{dia}^{-1}$, $\mathrm{td}_{\mathrm{zc}}$ teórico de 90 segundos e razão de recirculação (p) de 0,05 com dispositivo de coleta de água flotada constituído de "fundo falso" (placa) com orifícios. Os resultados apresentados na Figura 13 não indicaram a presença
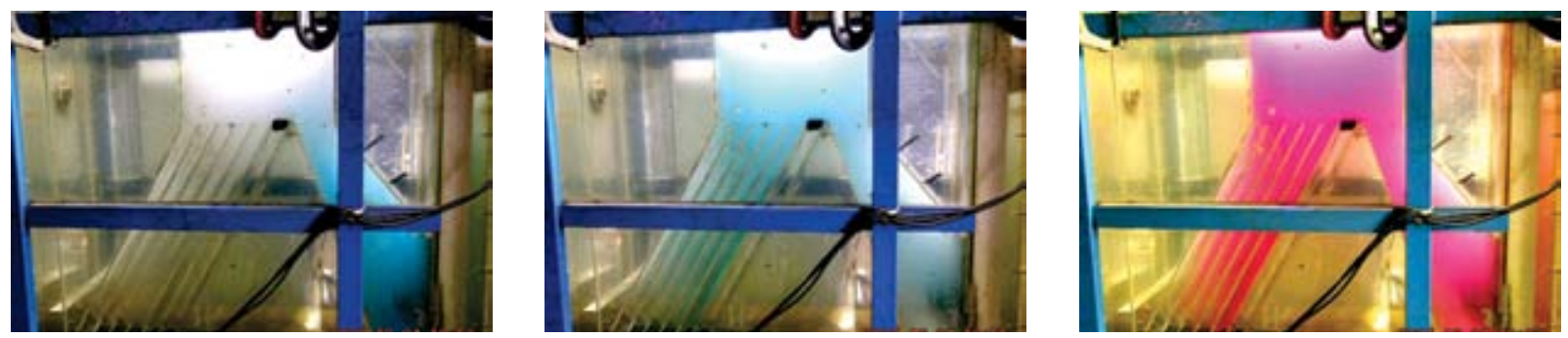

Figura 9 - Algumas das imagens dos ensaios com uso de traçadores, mostrando a distribuição do escoamento de líquido entre as lamelas em três momentos subsequentes da unidade operando no modo de alta taxa. Taxa de $460 \mathrm{~m}^{3} \cdot \mathrm{m}^{-2} \cdot \mathrm{d}^{-1}, p=0,10, T d_{z c}=90 \mathrm{~s}$ e a saída de água flotada feita através de placa com orifícios localizada logo abaixo do conjunto de lamelas (dispositivo Tipo 2). 

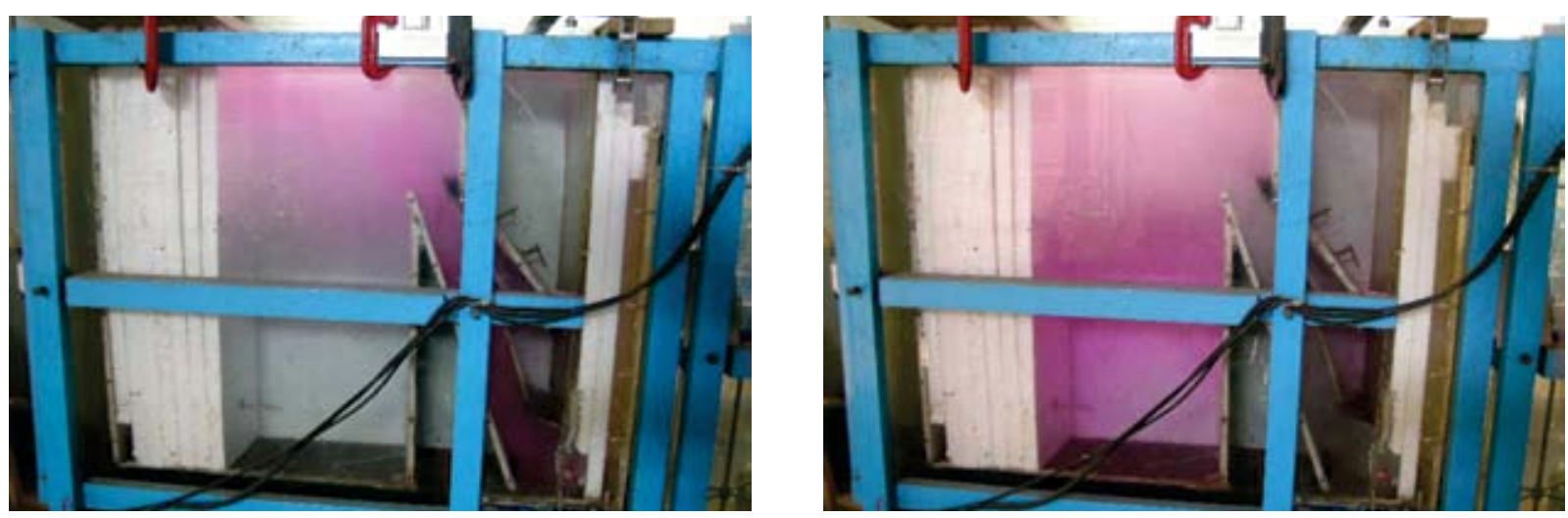

Figura 10 - Algumas das imagens dos ensaios com uso de traçador que envolveram a definição das condições de coleta da água flotada na unidade, operando com modo convencional. Taxa de $200 \mathrm{~m}^{3} \cdot \mathrm{m}^{-2} \cdot \mathrm{d}^{-1}, p=0,10, \mathrm{Td}_{\mathrm{zc}}=40 \mathrm{~s}$ e a saída da água flotada feita placa com orifícios (dispositivo Tipo 2) localizada na porção inferior da zona de separação.

de zona morta, pois o valor de $\Theta$ foi sempre $<1$ (Figura 13-a). No entanto, a Tabela contida na Figura 13-b mostra um aumento da dispersão no tanque de FAD quando comparada com os resultados da Figura 12. O valor obtido foi de 0,16 , tendendo a uma dispersão moderada. $\mathrm{O}$ escoamento apresentou maior tendência a mistura completa, quando comparado aos demais ensaios, pois foi menor a extensão do escoamento, tendendo ao pistonado (tempo de residência modal foi de 0,70 ) e o valor de $\sigma^{2}$ foi de 0,33. A Figura 13-b, referente ao modelo de tanques em série, apresenta um bom ajuste da reta de regressão aos pontos experimentais e se mostrou mais adequado para descrever o comportamento do fluxo da unidade de flotação como um todo.

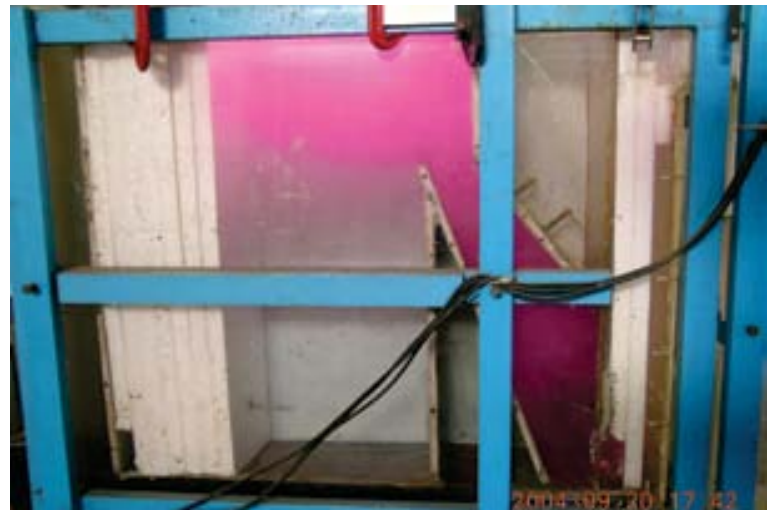

A Figura 14 apresenta os resultados dos ensaios de estímulo e resposta para o tanque de flotação da unidade piloto de FAD investigada, operando com TAS ${ }_{z . s}$ de $200 \mathrm{~m}^{3} \cdot \mathrm{m}^{-2} \cdot \mathrm{d}^{-1}, \mathrm{td}_{\mathrm{zc}}$ teórico de 90s e razão de recirculação (p) de 0,10 , com dispositivo de coleta de água flotada constituído de "fundo falso" (placa) com orifícios. Os resultados apresentados na Figura 14 não indicaram a presença de zona morta, pois o valor de $\Theta$ foi sempre $<1$ (Figura 14-a). No entanto, a Tabela contida na Figura 14-b mostra um aumento da dispersão no tanque de FAD quando comparada com os resultados da Figura 12 e 13. O valor obtido foi de 0,18, tendendo a uma dispersão moderada. O escoamento apresentou maior tendência a mistura completa, quando comparado aos demais

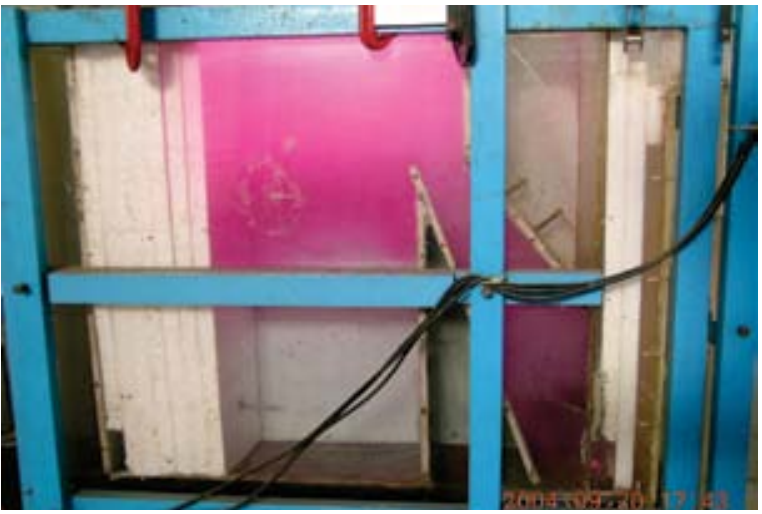

Figura 11- Algumas das imagens dos ensaios de traçador que envolveram a definição das condições de coleta da água flotada na unidade, operando no modo convencional. Taxa de $200 \mathrm{~m}^{3} \cdot \mathrm{m}^{-2} \cdot \mathrm{d}^{-1}, p=0,10, \mathrm{Td}_{z c}=90 \mathrm{~s}$ e a saída da água flotada feita através de placa com orifícios (dispositivo Tipo 2) localizada na porção inferior da zona de separação. 


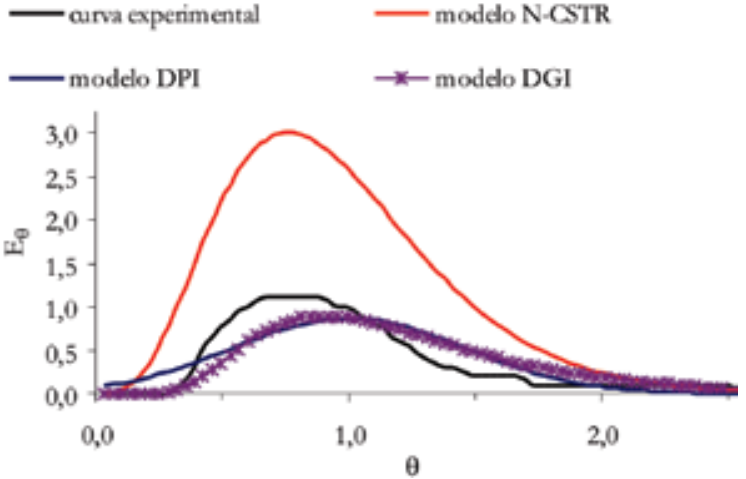

(a)

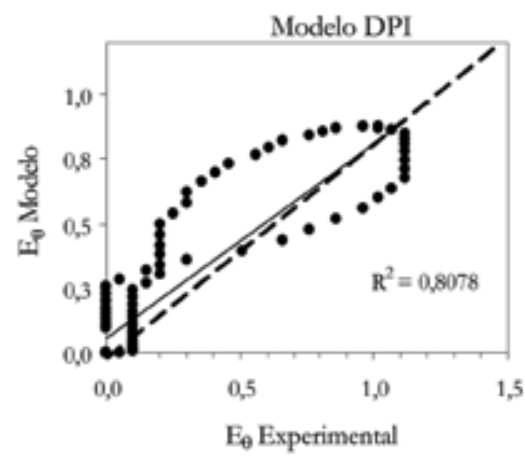

(c)

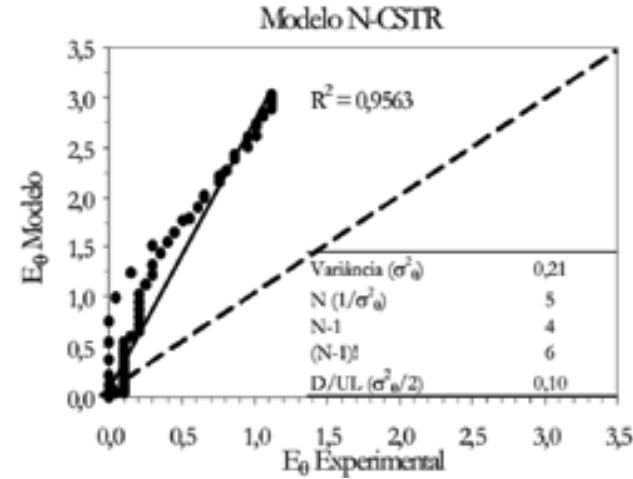

(b)

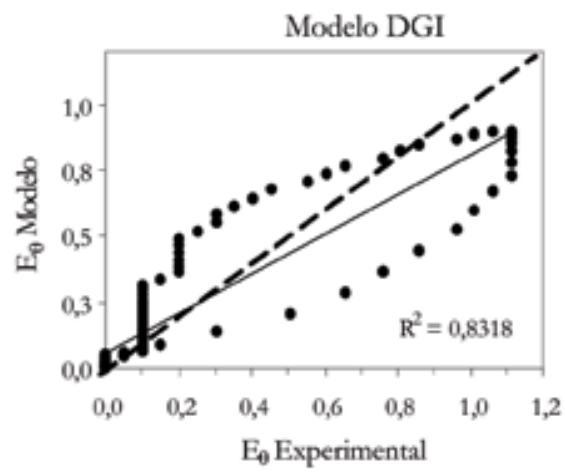

(d)

Figura 12- Curvas normalizadas referentes aos ensaios estímulo-resposta na unidade piloto de FAD, operando no modo convencional para $T_{\mathrm{zS}}$ de $125 \mathrm{~m}^{3} \cdot \mathrm{m}^{-2} \cdot \mathrm{d}^{-1} ; \mathrm{p}$ 0,10; $\mathrm{td}_{\mathrm{zc}}$ teórico na zona de contato de 40s, com dispositivo de coleta de água flotada constituído de fundo falso (placa) com orifícios (Tipo 2). a) curvas experimentais e teóricas; b) ajuste para o modelo de tanques em série (N-CSTD); c) ajuste para modelo de pequena dispersão (DPI) ; d) ajuste para o modelo de grande dispersão (DGI). Tempo de detenção experimental de 14 minutos. Ensaio realizado com solução concentrada de NaCl de 300 g.L.1 1 aplicada no volume de 20ml no modo pulso. Equipamento utilizado: TI-89 Texas Instruments conjugado a CBL2 e software TI-Graph Link 89.

ensaios, pois foi menor a extensão do escoamento, tendendo ao pistonado (tempo de residência modal foi de 0,65$)$ e o valor de $\sigma^{2}$ foi de 0,37. A Figura 14-b, referente ao modelo de tanques em série, apresenta um bom ajuste da reta de regressão aos pontos experimentais e se mostra mais adequado para descrever o comportamento do fluxo da unidade de flotação como um todo.

A Figura 15 apresenta os resultados dos ensaios de estímulo e resposta para o tanque de flotação da unidade piloto de FAD investigada, operando com $\mathrm{TAS}_{z \mathrm{~s}}$ de $200 \mathrm{~m}^{3} \cdot \mathrm{m}^{-2} \cdot \mathrm{d}^{-1}$, $\mathrm{td}_{\mathrm{zc}}$ teórico de 40 s e razão de recirculação (p) de 0,10 , com dispositivo de coleta de água flotada constituído de "fundo falso" (placa) com orifícios. Assim como em todos os ensaios realizados com o tanque de FAD, verificou-se através dos resultados apresentados na Figura 15 que o escoamento não indicou a presença de zona morta, pois o valor de $\Theta$ foi sempre $<1$ (Figura 15-a). A Tabela contida na Figura 15-b mostra uma pequena diminuição da dispersão no tanque de FAD quando comparada com os resultados da Figura 14 . O valor obtido foi de 0,16 , tendendo a uma dispersão moderada. $\mathrm{O}$ escoamento apresentou maior tendência ao pistonado (tempo de residência modal foi de 0,70) quando comparado ao resultado da Figura 14 e o valor de $\sigma^{2}$ foi de 0,32. Mais uma vez, o modelo de tanques em série, apresentou um bom ajuste da reta de regressão 


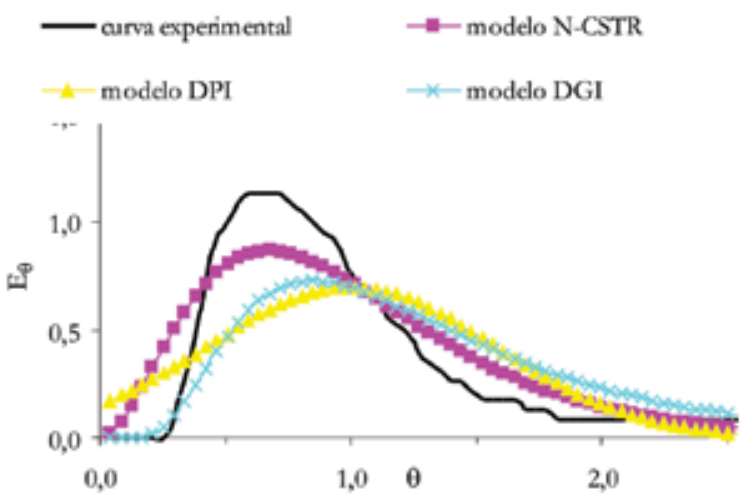

(a)

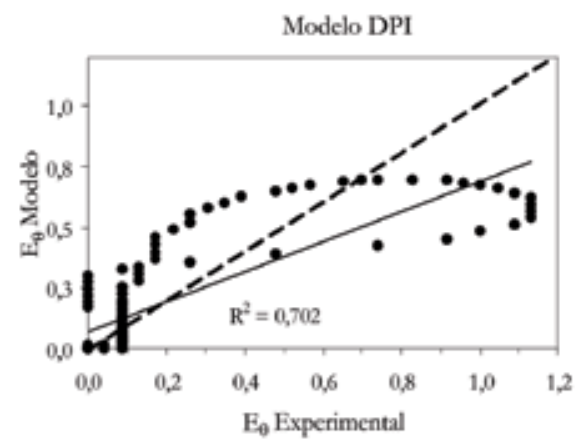

(c)

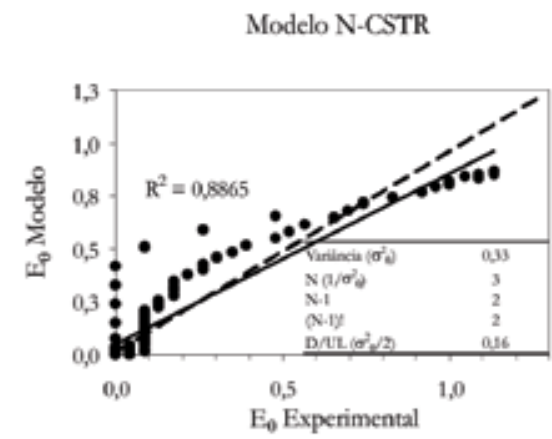

(b)

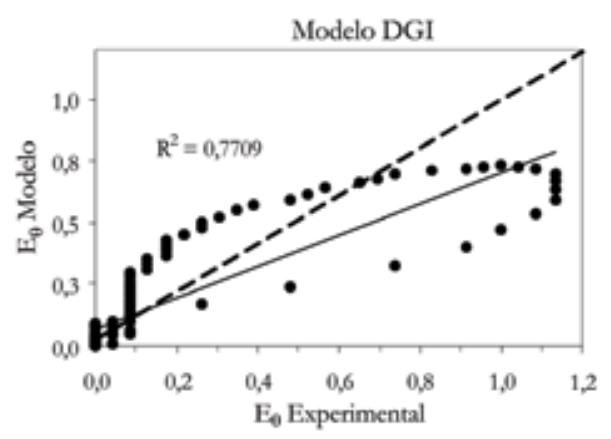

(d)

Figura 13- Curvas normalizadas referentes aos ensaios estímulo-resposta na unidade piloto de FAD, operando no modo convencional para $T_{A S}$ de $200 \mathrm{~m}^{3} \cdot \mathrm{m}^{-2} \cdot \mathrm{d}^{1} ; \mathrm{p}=0,05 ; \mathrm{td}_{z c}$ na zona de contato de 90s, com dispositivo de coleta de água flotada constituído de "fundo falso" (placa) com orifícios. a) curvas experimentais e teóricas; b) ajuste para o modelo de tanques em série (N-CSTD); c) ajuste para modelo de pequena dispersão (DPI); d) ajuste para o modelo de grande dispersão (DGI). Tempo de detenção experimental de 11,8 minutos. Ensaio realizado com solução concentrada de $\mathrm{NaCl}$ de 300 g.L.1 aplicada no volume de $20 \mathrm{ml}$ no modo pulso. Equipamento utilizado: TI-89 Texas Instruments conjugado a CBL2 e software TI-Graph Link 89.

aos pontos experimentais e se mostrou mais adequado para descrever o comportamento do escoamento no interior da unidade de flotação como um todo (Figura 15-b).

\section{Considerações finais}

A instalação piloto, quando operando no modo de alta taxa (com módulos lamelares) e com o dispositivo de coleta de água flotada Tipo 1 (composto por tubo perfurado com escoamento livre implantado na superfície da região de saída do flotador), apresentou distribuição inadequada da vazão afluente à zona de separação, independentemente dos valores de TAS, p ou $\mathrm{Td}_{\mathrm{zc}}$ aplicados. Ou seja, em todas as situações verificou-se, através da análise de imagens após aplicação de traçadores, uma di- visão bastante desigual da vazão entre os espaços interlamelares do módulo de alta taxa presente no interior da zona de separação da piloto.

Posteriormente, foram estudadas as configurações, envolvendo o "fundo falso" com orifícios distribuídos na parte inferior da unidade, na região situada logo abaixo do módulo de placas (Dispositivo de coleta Tipo 2). O dispositivo Tipo 2 apresentou-se como a melhor alternativa investigada, tanto para operação como unidade convencional quanto de alta taxa. No entanto, observou-se que esse último dispositivo, quando no modo de operação de alta taxa, embora tenha se mostrado como a melhor opção, não foi capaz de promover distribuição perfeitamente equitativa de vazão 


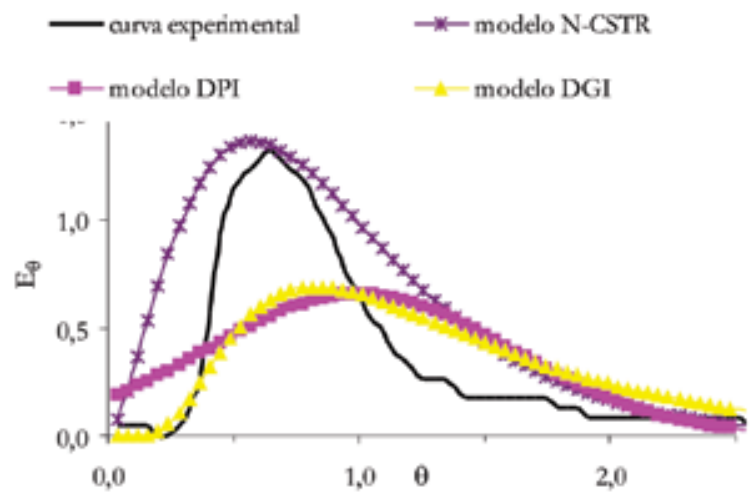

(a)

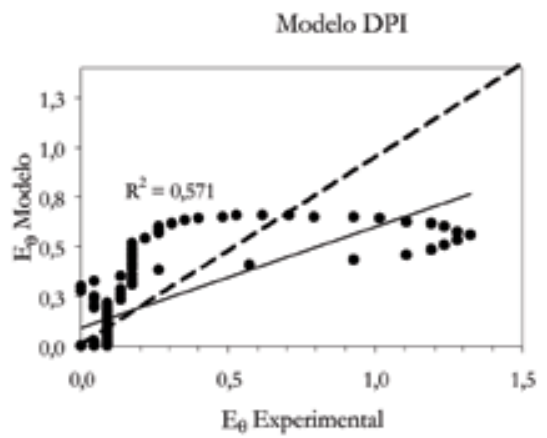

(c)

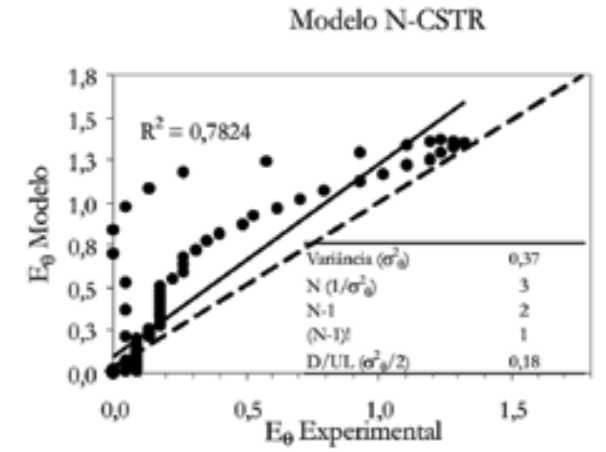

(b)

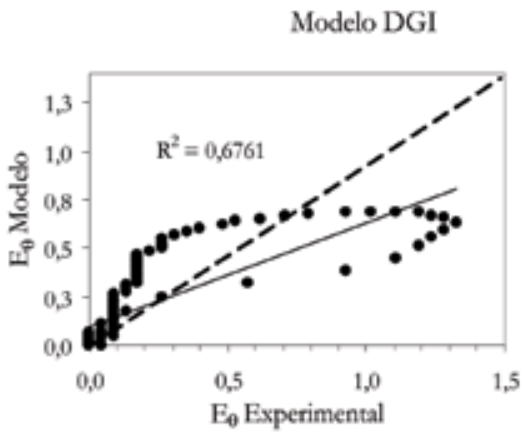

(d)

Figura 14 - Curvas normalizadas referentes aos ensaios estímulo-resposta na unidade piloto de FAD, operando no modo convencional para $T_{\mathrm{zS}}$ de $200 \mathrm{~m}^{3} \cdot \mathrm{m}^{-2} \cdot \mathrm{d}^{-1} ; \mathrm{p}$ 0,10; $\mathrm{td}_{\mathrm{zc}}$ na zona de contato de 90s, com dispositivo de coleta de água flotada constituído de "fundo falso" (placa) com orifícios. a) curvas experimentais e teóricas; b) ajuste para o modelo de tanques em série (N-CSTD); c) ajuste para modelo de pequena dispersão (DPI); d) ajuste para o modelo de grande dispersão (DGI). Tempo de detenção experimental de 12,32 minutos. Ensaio realizado com solução concentrada de NaCl de 300 g.L.1 aplicada no volume de $20 \mathrm{ml}$ no modo pulso. Equipamento utilizado: TI-89 Texas Instruments conjugado a CBL2 e software TI-Graph Link 89.

entre as lamelas presentes na zona de separação. Este fato foi atribuído à reduzida escala da unidade piloto investigada.

No caso da operação no modo convencional, para estudar as condições de interesse no que tange aos valores mais elevados de TAS (até $500 \mathrm{~m}^{3} \cdot \mathrm{m}^{-2} \cdot \mathrm{d}^{-1}$ ), foi necessário reduzir a largura e comprimento (em planta) da zona de separação da unidade piloto para cerca de $40 \%$ da área original. Este fato pode ter dificultado uma distribuição mais equânime da água entre as lamelas e constituído parte do problema que antes era somente atribuído às condições inadequadas de coleta de água flotada observadas quando o dispositivo de coleta Tipo 1 foi utilizado.

Acredita-se que as unidades FAD de alta taxa em escala plena sejam menos influenciadas por esta questão, uma vez que possuem espaço suficiente para que seja adotada uma posição (distância da parte inferior das lamelas) e configuração adequadas do sistema de coleta de água flotada do Tipo 2. Todavia, os padrões de escoamento identificados na análise qualitativa, e quando o sistema operava no modo convencional com sistema de coleta superior, foram similares aos obtidos por Amato e Wick (2009).

De forma geral, comparando-se os resultados dos ensaios estímulo-resposta realizados no tanque de flotação da unidade piloto investigada, nota-se que o aumento da recirculação ocasionou aumento da dispersão do escoamento. Salvo as diferentes geometrias, tais resultados são concordantes com os encontrados por Shawwa 


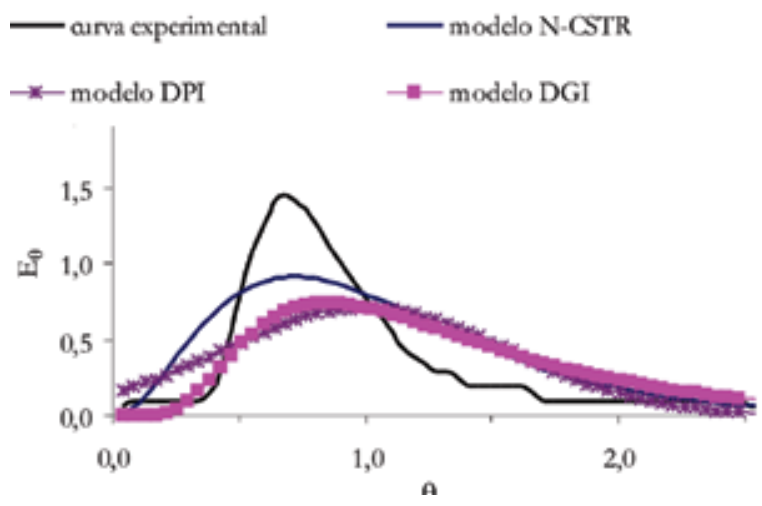

(a)

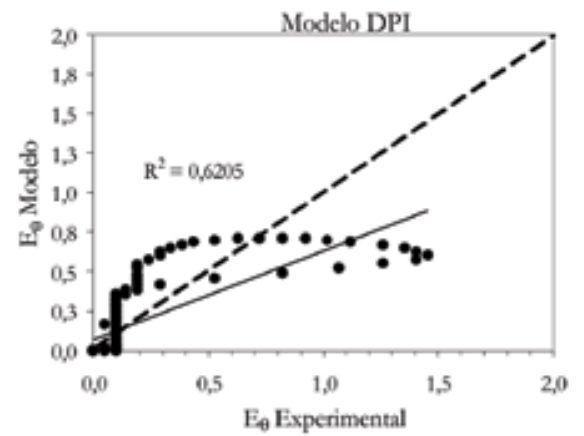

(c)

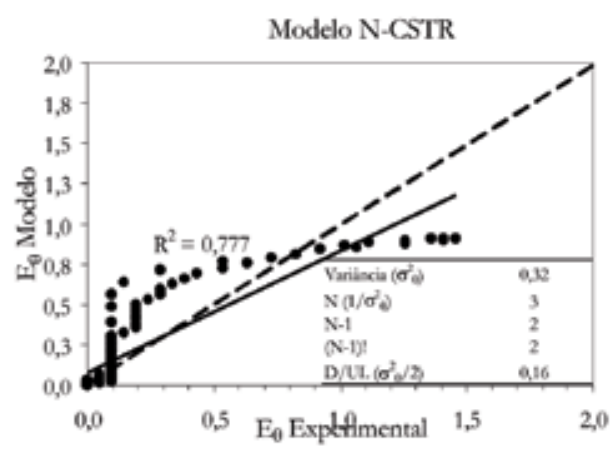

(b)

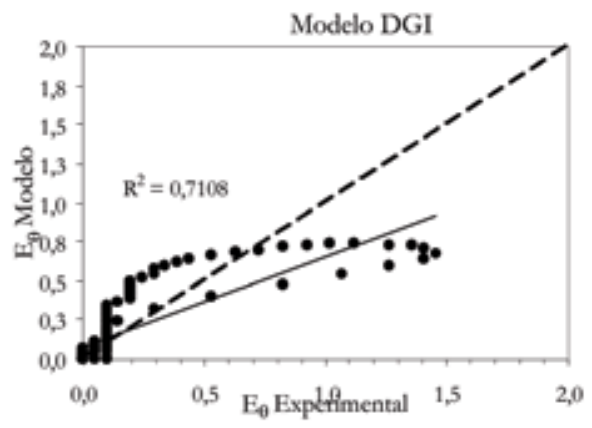

(d)

Figura 15- Curvas normalizadas referentes aos ensaios estímulo-resposta na unidade piloto de FAD, operando no modo

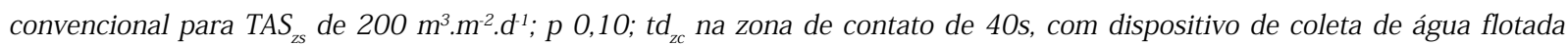
constituído de "fundo falso" (placa) com orifícios. a) curvas experimentais e teóricas; b) ajuste para o modelo de tanques em série (N-CSTD); c) ajuste para modelo de pequena dispersão (DPI); d) ajuste para o modelo de grande dispersão (DGI). Tempo de detenção experimental de 11,73 minutos. Ensaio realizado com solução concentrada de $\mathrm{NaCl}$ de 300 g.L.1 aplicada no volume de $20 \mathrm{ml}$ no modo pulso. Equipamento utilizado: TI-89 Texas Instruments conjugado a CBL2 e software TI-Graph Link 89.

e Smith (1998), que também verificaram o aumento no grau de mistura com o aumento de $p$, através da análise do adimensional número de Peclet (Pe), obtido por meio de ensaios estímulo-resposta. Verificou-se adicionalmente que, para as mesmas condições operacionais, o incremento de $\mathrm{p}$ ocasionou um aumento do tempo de residência do tanque de FAD.

\section{Conclusões}

A análise dos resultados referentes à definição do sistema de coleta de água flotada permite concluir que:

O sistema de coleta de água flotada Tipo 1, implantado na parte superior da região localizada após o anteparo de saída da unidade, não foi capaz de proporcionar coleta uniforme da água flotada;

O dispositivo de coleta de água flotada Tipo 2 , constituído por placa com orifícios colocada na região abaixo das placas, proporcionou melhor desempenho para coleta de água flotada com maior uniformidade das linhas de corrente na região da zona de separação da unidade FAD, tanto no modo de operação convencional quanto no modo de operação com alta taxa (obtido com a inserção de módulo lamelar na ZS da unidade piloto);

De modo geral, o modelo de tanque em série mostrou um bom ajuste da reta de regressão aos pontos experimentais, bem como uma maior aproximação da reta de ajuste perfeito, sendo mais adequado para descrever o comportamento do fluxo da unidade de FAD. 


\section{Lista de símbolos}

DGI - modelo de grande dispersão

DPI - modelo de pequena dispersão

E $\theta$ - curvas normalizadas do traçador

FAD - Flotação por ar dissolvido

L.h ${ }^{-1}$ - Litros por hora

$\mathrm{m}^{3} \mathrm{~m}^{-2} \mathrm{dia}^{-1}$ - metros cúbicos por metro qua-

drado por dia

N-CSTR - modelo de tanques em série

p - recirculação de água saturada

TAS - Taxa de aplicação superficial

TAS $_{z . c}$ - Taxa de aplicação superficial na zona de clarificação

$\mathrm{Td}_{\mathrm{zs}}$ - tempos de detenção na zona de clarificação

$\mathrm{Td}_{\mathrm{zc}}$ - tempos de detenção na zona de contato

$\theta$ - tempo adimensional

\section{Referências bibliográficas}

AMATO, T.; WICKS, J. (2009). The practical application of computational fluid dynamics to dissolved air flotation, water treatment plant operation, design and development. Journal of Water Supply: Research and Technology. AQUA, 58, 1, pp. 65-73.

BONDELINDA,M.; SASICB, S.; KOSTOGLOUC, M.; BERGDAHLA, L.; PETTERSSONA, T.J.R. (2010). Single- and two-phase numerical models of Dissolved Air Flotation: Comparison of 2D and 3D simulations. Colloids and Surfaces A: Physicochem. Eng. Aspects 365 (2010) p. 137-144.

COELHO, E.R.C.; REALI, M.A.P.; CAMPOS, J.R. (1991) Emprego da flotação por ar dissolvido na clarificação de águas para abastecimento: influência da taxa de aplicação superficial. In: CONGRESSO BRASILEIRO DE ENGENHARIA SANITÁRIA E AMBIENTAL, 16., 1991, Goiânia, GO. Anais... Goiânia, GO: ABES, 1991. v. 2, p. 215-231.

DOMBROSKI, S.A.G.; REALI, M.A.P.; MARCHETTO, M. (1996) Método eficiente para o tratamento de água com cor elevada e baixa turbidez: flotação por ar dissolvido. In: SIMPÓSIO ÍTALO-BRASILEIRO DE ENGENHARIA SANITÁRIA E AMBIENTAL, 3., 1996, Gramado, RS. Anais... Gramado, RS: ABES/ANDIS. v.1.

EDZWALD, J.; HAARHOFF, J. (2011). Dissolved air flotation for water clarification. McGraw-Hill, 352 p.
EDZWALD, J.K. (1999) Integrating high-rate DAF technology into plant design. J. AWWA., v. 91, n. 12, Dec. 1999.

EDZWALD, J.K.; MALLEY, J.P. (1991) Laboratory comparison of DAF with convencional treatment. J. AWWA Res. Tech., p. 56-61.

FERGUSON, C.; LOGSDON, G.S.; CURLEY, D. (1995) Comparison of dissolved air flotation and direct filtration. Wat. Sci. Tech., v. 31, n. 3-4, p. 113-124.

HEINANEN, J.; JOKELA, P.; ALA-PEIJARI, T. (1995) Use of dissolved air flotation in potable water treatment in Finland. In: IVES, K.J.; BERNHARDT, H.J. (Eds.). Flotation processes in water and sludge treatment. Wat. Sci. Tech., Great Britain, v. 31, n. 3-4, p. 225-238.

LAKGHOMI, B.; LAWRYSHYN, Y.; HOFMANN, R. (2012). Importance of flow stratification and bubble aggregation in the separation zone of a dissolved air flotation tank. Water Research 46. p. 4468 - 4476.

Levenspiel, O. (1999) Chemical Engineering Reactor. 3rd edition. John Wiley \& Sons, New York.

LUNDH, M.; JÖNSSON, L.; DAHLQUIST, J. (2002) The influence of contact zone configuration on the flow structure in a dissolved air flotation pilot plant. Wat. Res., v. 36, p. 15851595.

MALLEY, J.P.; EDZWALD, J.K. (1991b) Concepts of dissolved-air flotation treatment of drinking waters. J. Wat. SRT-Aqua, v. 40, n. 1, p. 7-17.

MARCHETTO, M.; REALI, M.A.P. (1997a) Concepção moderna de unidades de flotação aplicada ao tratamento de água. In: SIMPOSIO INTERNAZIONALE DI INGEGNERIA SANITARIA AMBIENTALE, 1997, Ravello, Villa Rufolo. Proceedings... Ravello, Villa Rufolo: ABES/ANDIS/ AIDIS/ATTI. p.758-765.

MORUZZI, R. B. (2005). Avaliação da Influência da Distribuição de Tamanho de Partículas e do Binômio Velocidade/Tempo de Detenção na Zona de Reação no Desempenho da Flotação com Utilização de Sonda Ultrassônica e Técnica de Análise por Imagem. Tese de doutorado, apresentada na Escola de Engenharia 
de São Carlos, Universidade de São Paulo. São Carlos: EESC - USP. 240p.

MORUZZI, R. B. e REALI, M. A. P. (2011). Characterization of micro-bubble size distribution and flow configuration in DAF contact zone by a non-intrusive image analysis system and tracer tests. . Wat. Sci. Tech., 61 (1), 253-262.

PATRIZZI, L.J. (2002) Remoção de ferro, manganês e substâncias húmicas de água para abastecimento, com uso de flotação por ar dissolvido de alta taxa e oxidação química. 2002. $220 \mathrm{f}$. Tese (Doutorado)-Escola de Engenharia de São Carlos, Universidade de São Paulo, São Carlos.

REALI, M.A.P.; CAMPOS, J.R. (1992) Projeto de câmaras de saturação de sistemas de flotação por ar dissolvido, com recheio de pvc.. In: CONGRESO INTERAMERICANO DE INGENIERIA SANITARIA Y AMBIENTAL, 23., La Habana, Cuba. Anais... La Habana, Cuba: AIDIS, 1992. v. 2, parte 1, p. 283-296.

REALI, M.A.P. ; MARCHETTO, M. (2001). High-rate dissolved air flotation for water treatment. Wat. Sci. Tech., v. 43, n. 8, p. 43-49.

REALI, M.A.P.; PATRIZZI, L.J. (2007). The influence of the contact zone configuration on the efficiency of a DAF pilot plant. In: The $5^{\text {th }}$ International Conference on Flotation. Flotation 2007: Flotation in Water and Watewater Systems. Proceedings Seoul, South Korea, sept.

REALI, M.A.P.; SANTOS, S.P. (1999) Emprego de uma unidade de flotação de alta taxa com escoamento vertical para remoção de algas de águas para abastecimento. Cad. Eng. San. Amb., São Carlos, v. 1, n. 1, p. 37-45.

SCHNEIDER, D.O. et al. (1991) Dissolved air flotation and polyaluminium chloride - an effective economical combination. In: AMERICAN WATER WORKS ASSOCIATION ANUAL CONFERENCE, WATER RESEARCH FOR THE NEW DECADE, Philadelphia, EUA. Proceedings $\cdots$ Philadelphia, EUA: IWWA, p. 367-383.

SCHOFIELD, T. (2000) Dissolved air flotation in drinking water production. Wat. Sci. Tech., v.43, n.8, p.9-18.

VALADE, M.T.; EDZWALD, J.K.; TOBIASON, J.E.; DAHLQUIST, J.; HEDBERG, T.; AMATO, T.
(1996) Particle Removal by flotation and filtration: pretreatment effects. J. AWWA., p. 3547.

VAN PUFFELEN, J.; BUIJS, P.J.; NUHN, P.N.A.M.; HIJNEN, W.A. M. (1995) Dissolved air flotation in potable water treatment: the Dutch experience. In: IVES, K. J.; BERNHARDT, H. J. (Eds.). Flotation processes in water and sludge treatment. Wat. Sci. Tech., Great Britain, v. 31, n. 3-4, p. 149-157.

YIANATOS, J.; DIÁZ, F. (2011). Hydrodynamic Characterization of Industrial Flotation Machines Using Radioisotopes 10/2011; ISBN: 978-953-307-510-5In book: Radioisotopes Applications in Physical Sciences. 